\title{
Agriculture Sector Growth and Inflation in Ethiopia: Evidence from Autoregressive Distributed Lag Model
}

\author{
Endalkachew Kabtamu Mekonen \\ Department of Economics, Wolkite University, Gubrei, Ethiopia \\ Email: endalkhabte@gmail.com, Endalkachew.kabtamu@wku.edu.et
}

How to cite this paper: Mekonen, E. K. (2020). Agriculture Sector Growth and Inflation in Ethiopia: Evidence from Autoregressive Distributed Lag Model. Open Journal of Business and Management, 8, 2355-2370. https://doi.org/10.4236/ojbm.2020.86145

Received: September 9, 2020

Accepted: October 11, 2020

Published: October 14, 2020

Copyright $\odot 2020$ by author(s) and Scientific Research Publishing Inc. This work is licensed under the Creative Commons Attribution International License (CC BY 4.0).

http://creativecommons.org/licenses/by/4.0/

\begin{abstract}
There is cross country difference about the relationship between economic growth and inflation. Although the issue is the most researched topic, limited studies were undertaken at sectoral level, such as the relationship between inflation and agriculture sector growth. Therefore, this study examines the effect of inflation on agriculture sector growth of Ethiopia from 1980-2018 using Autoregressive Distributed Lag model. Inflation has negative and significant long-run relation with agriculture sector growth suggesting that inflation is harmful to agriculture sector growth than stimulating it. Other regressors such as total factors productivity, arable land and labour force growth have positive and significant long-run relationship with agriculture growth. In the short run, the growth of agriculture sector has positive and significant relationship with its lagged value, capital, labour force, factors productivity, inflation and exchange rate. Thus, to increase the growth of agriculture sector, government should moderate inflation using prudent monetary and fiscal policy. It should also monitor the efficacy and suitability of agriculture investment to countries context. As land is fixed input, intensive agriculture and productivity enhancing technologies should be applied. Increasing labour skill through training could also increase agriculture output.
\end{abstract}

\section{Keywords}

Agriculture Sector Growth, Autoregressive Distributed Lag Model, Ethiopia, Inflation, Total Factor Productivity

\section{Introduction}

In Ethiopia, agriculture sector is considered as the driver of poverty reduction, 
creation of employment opportunities, and export earnings. During the past decades, agriculture sector accounts $50 \%$ of GDP, employing $85 \%$ of the labour force, accounting $90 \%$ of the foreign exchange (NPC, 2016 and NBE, 2015) ${ }^{1}$. The sector is continued to be the key source of employment compared to the service and industry sector. The average growth rate of the three sectors from 1980-2018 is shown in Table 1. During the past four decades, the growth rate of agriculture sector was robust and has showed a sustained growth although it was sluggish compared to the growth rate of the service and industry sector. In the same way, the industry and service sector have exhibited a robust and continued growth in the same period. The average growth rate of service sector was $11.96 \%$ which exceeds the growth rate of agriculture and industry sectors which is $3.93 \%$ and $8.30 \%$, respectively.

Previously, Ethiopia is considered as a low inflation economy. However, it was no longer considered as a low inflation economy where the general price level raised to 45\% in 2007 and 2008 (UNDP, 2014), the maximum price level observed in the country history. In addition, Inflation was increased by $33.25 \%$ where food price reached to $40 \%$ in 2012. As shown in Table 1, inflation rate of Ethiopia as measured by consumer price index (CPI) was increased from $4.6 \%$ in (1980-1989) to $13.65 \%$ (2010-2018). Thus, the general price level has showed a continued percentage increase. Therefore, even though Ethiopia is achieving a high level of economic growth, the level of inflation is also high. On the other hand, the ultimate objective of policy makers is to attain rapid economic growth and maintain stable price level. Because, high economic growth is expected to reduce poverty and stable (low) price level is also expected to maintain the purchasing power of money in the economy. As a result of this fact, agriculture is the most priority sector in developing countries, because its share of GDP, employment, and foreign exchange earnings is high. It is also considered that development of the sector will lead to industrialization of the economy and poverty reduction. At the same time, inflation is increasingly become a public concern. Therefore, investigating the relationship between agriculture growth and inflation is vital for theoretical and empirical purpose.

Table 1. Average Sectoral growth and Inflation rate (1980-2018).

\begin{tabular}{ccccc}
\hline year & Agriculture & Service & Industry & Inflation rate (average) \\
\hline $1980-1989$ & 1.37 & 12.9 & 4.82 & 4.60 \\
$1990-1999$ & 2.14 & 8.91 & 1.78 & 7.53 \\
$2000-2009$ & 6.95 & 12.52 & 8.58 & 10.25 \\
$2010-2018$ & 5.46 & 10.13 & 18.03 & 13.65 \\
Average & $\mathbf{3 . 9 8}$ & $\mathbf{1 1 . 9 6}$ & $\mathbf{8 . 3 0}$ & $\mathbf{9 . 0 1}$ \\
\hline
\end{tabular}

Source: Complied from NBE, and WB (2020).

${ }^{1}$ NPC refers to the National Planning Commission of Ethiopia, NBE stands for the National Bank of Ethiopia, and UNDP is an abbreviation to united nation development program. 
At aggregate level, considerable studies were undertaken that investigate the effect of inflation on economic growth. For instance, Getachew (2018), Ashagrie (2015), Fekadu (2012), and Gokal and Hanif (2004) shown the relationship between inflation and economic growth in Ethiopia. However, little is known about the effect of inflation on sectoral growth such as agriculture, industry and service sector. Therefore, investigating the relationship between inflation and sectoral growth could give a new insight for policy makers to design appropriate economic policy. For instance, Ayyoub (2015) revealed examining the effect of inflation on sectoral growth is useful due to the following reasons. First, there may variation between short-run and long-run growth determinants of aggregate economic and sectoral growth. Second, evidence obtained from various sectors is helpful to identify growth patterns and economic policy transmission channels. Therefore, investigating the effect of inflation on economic growth at sectoral level has theoretical and practical relevance. In Ethiopia, agriculture sector is thought as vital because majority of Ethiopians depends on it for their livelihood. Even though the share of agriculture in the overall economy is decreasing, it remains a major source of employment which accounts almost 70\% of employment (Louhichi et al., 2019). Ethiopia's government is concerned to increase growth of agriculture, and maintain inflation to a single digit. However, there are various arguments about the relationship between growth and inflation and whether policy maker can maintain a balance between these two objectives.

Therefore, the various arguments regarding whether inflation stimulates or harms economic growth are an unsettled topic that needs country and sector specific study. As per the researcher knowledge, so far the relationship between inflation and agriculture growth has been disregarded and no studies have been undertaken in Ethiopia. Within this background, it is interesting to explore the nexus between inflation and agriculture sector growth. For the reason that disaggregate analysis of the nexus between inflation and agriculture growth will give policy makers a profound understanding and inform them to design proper policy mix in growth and stabilization strategies of economy. The major problem in setting growth target and stabilization policies in developing countries is how to align the two major macroeconomic objectives. Thus, looking at the nature of their nexus at disaggregate level is very fascinating particularly, in countries where agriculture is the major contributor of GDP, employment and export earnings. Thus, the general objective of the study is to examine the effect of inflation on agriculture sector growth. The rest of the study is organized as follow. Section two presents empirical literature review, section three discusses about the methodology, section four focuses on the analysis and discussion, and the last section presents the conclusion and recommendations.

\section{Literature Review}

Inflation, a persistent rise in the general price level of goods and service is the most important macroeconomic variables that need the careful attention of pol- 
icy makers. Agriculture is also the most vital and dominant economy particularly in developing countries. Both in theory and empirical findings, there are controversy about relationship between inflation and growth. An empirical study by Ayyoub (2015) showed that inflation and sectoral growth in developing economies using country panel data. Then, inflation has positive effect on agriculture sector growth. However, contrasting evidence found by Kaur (2013) who showed the negative effect of inflation on agriculture sector growth of India. Moreover, a study by Mkhatshwa et al. (2015) showed the negative relationship between inflation and agriculture sector growth in Swaziland. A study by Oyakhilomen and Rekwot (2014) examined the relationships of inflation trend, agricultural productivity and economic growth in Nigeria using granger causality test and found that the trend of inflation has significantly granger cause agricultural productivity. Therefore, the substantiation from the various literatures indicated that there exists mixed evidence on the effect of inflation on agriculture growth. In this regard, the presence of mixed evidence could due to the difference in the methodology used by researchers.

\section{Methodology of the Study}

Secondary data compiled from National Bank of Ethiopia, Ministry of Finance and Economic Development and World Development indicators was used to achieve the study objective. Classical growth accounting approach is the base to develop the empirical model. The model is primarily used to derive agricultural total factor productivity (TFP). In many empirical works such as Verdu et al. (2019), Ndour (2017), and Bachewe (2012), agriculture output $(Y)$ is a function of labour $(L)$, capital $(K)$ and land $(L a)$ which is written as Equation (1).

$$
Y=f(L, K, L a)
$$

Following Equation (1), the production function is specified as Equation (2).

$$
Y=A L^{\alpha} K^{\beta} L a^{\delta}
$$

where $\alpha, \beta$, and $\delta$, denotes income shares of labour, capital and land in agriculture output, respectively. Moreover, A denotes total factor productivity (Solow residual) which explain change in output unexplained by the inputs. Taking the natural logarithm of Equation (2) gives Equation (3).

$$
\ln Y=\ln A+\alpha \ln L+\beta \ln K+\delta \ln L a
$$

By differentiating Equation (3) with respect to time, we can the growth of agriculture which is written as Equation (4).

$$
\frac{\mathrm{d} Y}{\mathrm{~d} t} \frac{1}{Y}=\frac{\mathrm{d} A}{\mathrm{~d} t} \frac{1}{A}+\alpha \frac{\mathrm{d} L}{\mathrm{~d} t} \frac{1}{L}+\beta \frac{\mathrm{d} K}{\mathrm{~d} t} \frac{1}{K}+\delta \frac{\mathrm{d} L_{a}}{\mathrm{~d} t} \frac{1}{L_{a}}
$$

where $\frac{\mathrm{d} Y}{\mathrm{~d} t} \frac{1}{Y}, \frac{\mathrm{d} A}{\mathrm{~d} t} \frac{1}{A}, \frac{\mathrm{d} L}{\mathrm{~d} t} \frac{1}{L}, \frac{\mathrm{d} L}{\mathrm{~d} t} \frac{1}{L}$, and $\frac{\mathrm{d} L_{a}}{\mathrm{~d} t} \frac{1}{L_{a}}$ are the growth of agriculture (GA), total factor productivity (TPF), labour force (LG), capital (KG), and arable land, respectively. Then Equation (4) is written as Equation (5). 


$$
\mathrm{GA}=\mathrm{TFP}+\alpha \mathrm{LG}+\beta \mathrm{KG}+\delta \mathrm{ALG}
$$

Then, from Equation (5) the TFP is solved as Equation (6).

$$
\mathrm{TFP}=\mathrm{GA}-(\alpha \mathrm{GL}+\beta \mathrm{KG}+\delta \mathrm{ALG})
$$

After estimating agricultural TFP, the next step is developing the empirical model by including additional regressors. Both theoretical and empirical literatures revealed that the growth of agriculture is not only determined by inputs, other factors can also affect its growth such as inflation and exchange rate. Therefore, the annual growth rate of agriculture is the dependent variable measured by its valued added. Inflation is measured by yearly growth rate of consumer price index. Labour is measured by growth rate of labour force; capital is measured by the gross capital formation (K) as a percentage of GDP, arable land is measured by the percentage of arable land to total land area. The exchange rate (RER) is measured by the real exchange rate of Birr in terms of other currency, usually US dollar. To investigate the long-run relationship among variables, an autoregressive distributed lag (ARDL) or bound cointegration test is employed developed by Pesaran et al. (2001) and Pesaran (1995). ARDL model has advantage over other methods of estimation, because in this model endogeneity problem is lesser, single relationship exists between dependent variable and exogenous variables, identification of cointegrating vector from multiple vectors is possible, and speed of adjustment can be derived from ARDL model without losing the long-run information (Nkoro \& Uko, 2016). ARDL model is suitable for different order of cointegration such as $\mathrm{I}(0), \mathrm{I}(1)$ or a hybrid of two, but it is not functional to $\mathrm{I}(2)$. To know whether variables in the model is $\mathrm{I}(0)$, $\mathrm{I}(1)$ or $\mathrm{I}(2)$, it is better to primarily undertake stationarity test of series. In estimating long-run relationship, two-step procedure is employed (Ahmed et al., 2013). In the first stage, existence of long-run relationship among the variables in the question is examined. In the second step, if long-run relation is established in first step, short and long-run parameters are estimated. The ARDL approach to cointegration includes the estimation of error correction of ARDL model for dependent variable and independent variables (El, 2018). Thus, the ARDL model formulation is given by Equation (7).

$$
\begin{aligned}
\Delta \mathrm{GA}_{t}= & \varnothing_{0}+\sum_{i=0}^{p} \beta_{1} \Delta \mathrm{GA}_{t-i}+\sum_{i=0}^{p} \beta_{2} \Delta \mathrm{TFP}_{t-i}+\sum_{i=0}^{p} \beta_{3} \Delta \mathrm{Lg}_{t-i} \\
& +\sum_{i=0}^{p} \beta_{4} \Delta \mathrm{P}_{t-i}+\sum_{i=0}^{p} \beta_{5} \Delta \mathrm{K}_{t-i}+\sum_{i=0}^{p} \beta_{6} \Delta \mathrm{AL}_{t-i} \\
& +\sum_{i=0}^{p} \beta_{7} \Delta \mathrm{RER}_{t-i}+\delta_{1} \mathrm{GA}_{t-1}+\delta_{2} \mathrm{TFP}_{t-1}+\delta_{3} \mathrm{Lg}_{t-1} \\
& +\delta_{4} \mathrm{P}_{t-1}+\delta_{5} \mathrm{~K}_{t-1}+\delta_{6} \mathrm{AL}_{t-1}+\delta_{7} \mathrm{RER}_{t-1}+\varepsilon_{t}
\end{aligned}
$$

where, $\Delta$ is the difference operator, $\varnothing_{0}$ is drift term, $p$ is the optimal lag length, $\beta_{1}$ to $\beta_{7}$ are the short-run dynamics of variables, $\delta_{1}$ to $\delta_{7}$ are long-run relationship of variables, and $\varepsilon_{t}$ is the error term. As documented in Nkoro and Uko (2016), the first step in ARDL model is testing the existence of long-run relation between variables under study using bound F-statistic. The bound cointegration test in ARDL model leads to hypothesis testing of the 
long-run relationship among the underlying variables. Thus, the null hypothesis assumes absence of long-run relationship i.e.

$H_{0}: \delta_{1}=\delta_{2}=\delta_{3}=\delta_{4}=\delta_{5}=\delta_{6}=\delta_{7}=0$; no cointegration (the long run relationship does not exist)

$H_{A}: \delta_{1} \neq \delta_{2} \neq \delta_{3} \neq \delta_{4} \neq \delta_{5} \neq \delta_{6} \neq \delta_{7} \neq 0$; cointegration (long run relationship does not exist)

The hypothesis is tested using Wald test (F-statistics) which give two sets of critical values. One set is lower critical bound denoted by $\mathrm{I}(0)$ which assumes no cointegration among variables. Another set is upper critical bound denoted by I(1) which assumes cointegration among variables (Pesaran et al., 2001). If the computed F-statistic is greater than upper bound critical value, then the null hypothesis is rejected i.e. the variables are cointegrated. In contrast, if F-statistic is less than the lower bound critical value, the null hypothesis is accepted which shows absence of cointegration among variables (Nkoro \& Uko, 2016). Besides, the result become inconclusive if the F-statistic value falls within the upper and lower bound critical value. If there is evidence of long run relationship among variables, the following long-run model (Equation (8)) is estimated.

$$
\begin{aligned}
\mathrm{GA}_{t}= & \varnothing_{0}+\sum_{i=0}^{p} \delta_{1} \mathrm{GA}_{t-i}+\sum_{i=0}^{p} \delta_{2} \mathrm{TFP}_{t-i}+\sum_{i=0}^{p} \delta_{3} \mathrm{Lg}_{t-i}+\sum_{i=0}^{p} \delta_{4} \mathrm{P}_{t-i} \\
& +\sum_{i=0}^{p} \delta_{5} \mathrm{~K}_{t-i}+\sum_{i=0}^{p} \delta_{6} \mathrm{AL}_{t-i}+\sum_{i=0}^{p} \delta_{7} \mathrm{RER}_{t-i}
\end{aligned}
$$

If there is long-run relationship, Error Correction Model (ECM) is employed to find the short-run dynamic of coefficient, denoted by ECM $(t-1)$ to show correction mechanism of disequilibrium in the model called speed of adjustment or feedback effect (Nkoro \& Uko, 2016). Hence, the ARDL specification of short run dynamics can be specified as Equation (9).

$$
\begin{aligned}
\Delta \mathrm{GA}_{t}= & \varnothing_{0}+\sum_{i=0}^{p} \beta_{1} \Delta \mathrm{GA}_{t-i}+\sum_{i=0}^{p} \beta_{2} \Delta \mathrm{TFP}_{t-i}+\sum_{i=0}^{p} \beta_{3} \Delta \mathrm{Lg}_{t-i} \\
& +\sum_{i=0}^{p} \beta_{4} \Delta \mathrm{P}_{t-i}+\sum_{i=0}^{p} \beta_{5} \Delta \mathrm{K}_{t-i}+\sum_{i=0}^{p} \beta_{6} \Delta \mathrm{AL}_{t-i} \\
& +\sum_{i=0}^{p} \beta_{7} \Delta \mathrm{RER}_{t-i}+\psi \mathrm{ECM}_{t-1} \varepsilon_{t}
\end{aligned}
$$

A number of diagnostic tests such as autocorrelation, normality, heteroscedasticity and stability test is undertaken to ascertain the goodness of fit of the ARDL model.

\section{Result and Discussion}

\subsection{Descriptive Analysis}

As shown in Table 2, all the variables are normally distributed as evidenced by Jarque-Bera test. During the study period, the average growth of agriculture was $3.94 \%$. The minimum level of growth rate was $(-20.88 \%)$ and $18.76 \%$ was the maximum growth rate. Similarly, inflation rate during the same period was $8.9 \%$, and the minimum and maximum were $(-9.81 \%)$ and $44.36 \%$, respectively. Average labour force growth was $3.27 \%$ and, respectively, its minimum and maximum value was $1.48 \%$ and $4.04 \%$. Concerning capital (K), its average value 
was $25.15 \%$ where the minimum and maximum was $12.87 \%$ and $40.67 \%$, respectively. Average arable land growth was $0.08 \%$ while the minimum and maximum was $(-0.03 \%)$ and $1.5 \%$, respectively. During the study period, the average total factors productivity (TFP) was $0.77 \%$, while minimum and maximum TFP was $(-11.24 \%)$ and $12.86 \%$, respectively. The average real exchange rate (RER) during the study period was 9.22, whereas the minimum and maximum RER was 2.07 and 28.91, respectively.

As displayed in Figure 1, price level was volatile, and prior to 2001, both positive and negative price growth was observed. However, after 2003, the price level becomes positive and the maximum price level was observed in 2007/8. Similarly, the agriculture sector growth was volatile. After 2003, growth of agriculture was positive although it has showed declining trend. Thus, there is no predictable pattern between inflation and agriculture sector growth of Ethiopia as shown in Figure 1.

Table 2. Descriptive analysis of variables.

\begin{tabular}{cccccccc}
\hline & AG & ALG & K & LG & P & TFP & RER \\
\hline Mean & 3.94 & 0.08 & 25.15 & 3.27 & 8.89 & 0.77 & 9.22 \\
Median & 5.17 & -0.04 & 23.83 & 3.36 & 7.82 & -0.60 & 8.14 \\
Maximum & 18.76 & 1.53 & 40.67 & 4.04 & 44.36 & 12.86 & 28.91 \\
Minimum & -20.88 & -0.30 & 12.87 & 1.48 & -9.81 & -11.24 & 2.07 \\
Std. Dev. & 8.34 & 0.39 & 7.09 & 0.52 & 10.98 & 7.94 & 7.60 \\
Skewness & -0.78 & 1.95 & 0.45 & -1.62 & 1.26 & 0.38 & 1.05 \\
Kurtosis & 3.89 & 6.80 & 2.72 & 6.20 & 5.33 & 2.39 & 3.16 \\
Jarque-Bera & 5.19 & 48.12 & 1.44 & 33.82 & 19.09 & 1.56 & 7.26 \\
Probability & 0.07 & 0.00 & 0.048 & 0.00 & 0.00 & 0.019 & 0.026 \\
\hline
\end{tabular}

Source, Author computation Using Eviews 9 (2020).

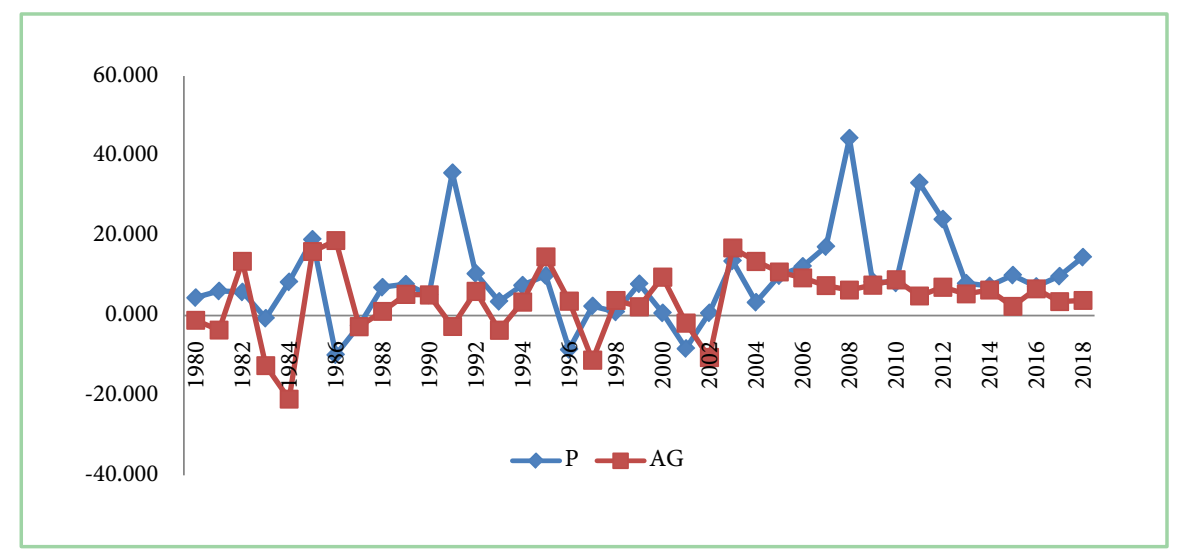

Figure 1. Inflation and agriculture sector growth (1980-2018). Source, Author compilation from various sources (2020). 
The developments of others regressors are presented in Figure 2. During the study period, more or less, the growth of arable land (ALG) and labour force (LG) were constant which showed a stable growth trajectory. On the other hand, the development of the total factor productivity (TFP) was so unpredictable, it fluctuates over the years. Concerning the real exchange rate (RER), it was continually increasing over the study period. Similarly, the trend of capital (K) shows an increment with slight fluctuation.

\subsection{Empirical Analysis}

In time series data analysis, the first task of researchers is test of stationarity to check whether variables are time dependent (presence of unit root) or not. Checking the presence of unit root helps researchers to avoid the possibility of running a spurious regression. In most empirical works, stationary test is checked by using Augmented Dickey-Fuller (ADF) unit root test. The null hypothesis of the ADF states that there is a unit root against the alternative that assumes stationarity of variable or absence of nit root. The decision rule is that if the ADF test (statistics) is greater than the critical value in absolute terms at $5 \%$ level of significance, then the null hypothesis of unit root is rejected, and vice versa. Following this rule, the ADF test result of this study is presented in Table 3.

As shown in Table 3, all variables are stationary at first difference that means they are integrated of order 1, I(1). Moreover, most variables are stationary at level such as AG, P, LG, TFP, $K$ and RER i.e. they are an integrated of order zero, $\mathrm{I}(0)$ at intercept except the RER. However, ALG is not stationary at level, it is integrated of order one, I(1). Therefore, there is a different order of co-integration. With different order of co-integration, testing the long-run relationship using the Johansen cointegration approach it is not applicable. If there is different order of cointegration, always $\mathrm{I}(0)$ and $\mathrm{I}(1)$, an autoregressive regressive distributed lag (ARDL) model is suitable (Pesaran et al., 2001). As a result, ARDL model is employed in this study to show the long-run relationship of AG with its regressors. After test of stationary, the next step in ARDL model is bound test of cointegration. The long-run relationship (cointegration) between AG and P, K, LG, ALG, TFP and RER is tested by using bound test of ARDL. As presented in Table 4, the bound test shows the presence of long-run relationship as evidenced by the F-statistic.

Where, $\mathrm{K}$ is the number of parameter estimated from ARDL model, $\mathrm{F}$ is calculated F-statistics, $\mathrm{I}(0)$ is the lower bound value, and $\mathrm{I}(1)$ is the upper bound value. Automatically, using the Akaike Information Criterion, ARDL (3, 3, 2, 2, 2,3 , and 3) was selected as the optimal lag length for the series.

\subsubsection{Estimation of the Long-Run and Short-Run Model}

In this section, the long-run and the short-run model is discussed as well as presented in Table 5 and Table 6 , respectively. The significance level of the variables under study can be judged by using the $t$ statistics. As a rule of thumb, if 
the absolute value of t-statistics is equal or greater than 2 , the variable is statistically significant at $5 \%$ or less $5 \%$ significant level. In addition, the significance level of variables can be judged by comparing the ratio of the coefficient of each variable by 2 with their respective standard error. If the calculated ratio obtained by dividing the coefficient of each variable by 2 is greater than their respective standard error, then the variable is statistically significant, other ways the variable under consideration is not statistically significant.

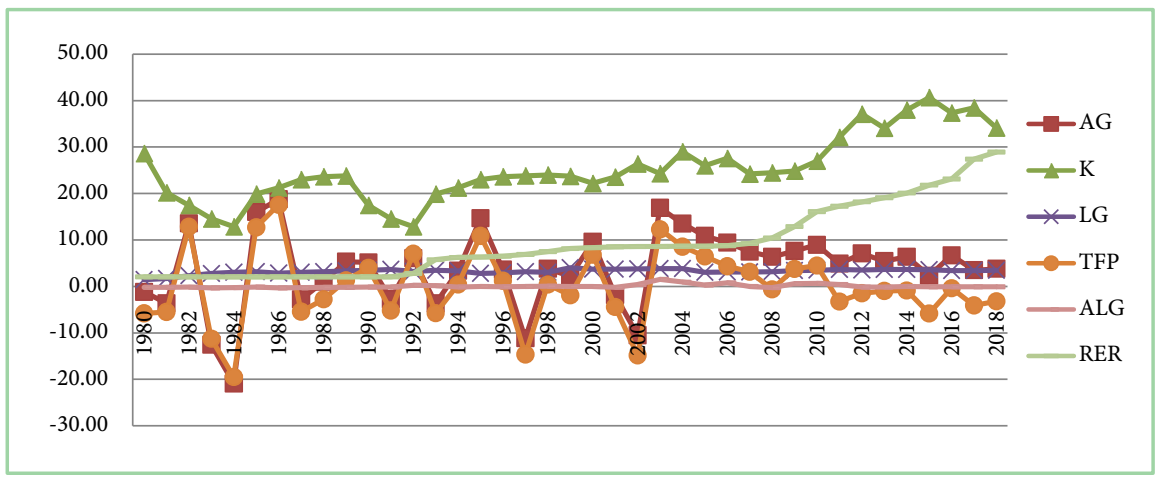

Figure 2. Trends of Variables (1980-2018). Source, Author compilation from various Sources (2020).

Table 3. Stationarity Test of variables.

\begin{tabular}{|c|c|c|c|c|c|}
\hline \multirow{2}{*}{ Variable } & \multicolumn{2}{|c|}{ At level, $\mathrm{I}(0)$} & \multicolumn{2}{|c|}{ ADF t-statistics at difference } & \multirow{2}{*}{$\begin{array}{c}\text { Order of integration } \\
\text { Decision }\end{array}$} \\
\hline & Intercept & Intercept \& trend & Intercept & Intercept \& trend & \\
\hline AG & $-5.758^{\star}$ & $-5.98^{\star}$ & $-10.019^{*}$ & $-9.858^{*}$ & $\mathrm{I}(0,1)$ \\
\hline $\mathrm{P}$ & $-4.719^{*}$ & $-5.023^{\star}$ & $-8.567^{\star}$ & $-8.435^{*}$ & $\mathrm{I}(0,1)$ \\
\hline ALG & -0.590 & -2.204 & $-3.212^{*}$ & $-3.344^{*}$ & $\mathrm{I}(1)$ \\
\hline LG & $-4.022^{*}$ & $-3.685^{*}$ & $-6.231^{*}$ & $-6.501^{*}$ & $\mathrm{I}(0,1)$ \\
\hline K & -1.244 & $-4.022^{*}$ & $-6.042^{\star}$ & $-5.852^{*}$ & $\mathrm{I}(0,1)$ \\
\hline TFP & $-6.304^{*}$ & $-6.213^{*}$ & $-7.031^{\star}$ & $-6.997^{*}$ & $\mathrm{I}(0,1)$ \\
\hline RER & $4.256^{\star}$ & 0.847 & $-3.280^{\star}$ & $-4.304^{\star}$ & $\mathrm{I}(0,1)$ \\
\hline
\end{tabular}

${ }^{*}$ MacKinnon (1996) with constant and $\quad{ }^{*}$ MacKinnon (1996) with constant \& no trend. no trend. critical values. $1 \%=-3.62$, $5 \%=-2.94$ and $10 \%$ level $=-2.60$ critical values. $1 \%=-3.62,5 \%=-2.94$ and $10 \%=-2.61$

${ }^{*}$ Mackinnon (1996), with constant \& trend. ${ }^{*}$ MacKinnon (1996) with constant \& trend. Critical critical values. $1 \%=-4.22,5 \%=-3.53$ and values. $1 \%=-4.23,5 \%=-3.54$ and, $10 \%=-3.20$. $10 \%=-3.20$ ${ }^{*}$ shows that the variable indicated are stationary at $5 \%$.

Source, Author computation Using Eviews 9 (2020).

Table 4. ARDL Bound Test of Cointegration.

\begin{tabular}{cccccccc}
$K$ & $\boldsymbol{F}$ & At 1\% Level of Significant & At 5\% Level of Significant & At & 10\% Level of Significant \\
\hline & & I(0) & I(1) & I(0) & I(1) & I(0) & I(1) \\
6 & 4.575 & 2.88 & 3.99 & 2.27 & 3.28 & 1.99 & 2.94
\end{tabular}

Source, Eview computation (2020) 
Table 5. The Long run Estimates of ARDL model.

\begin{tabular}{ccccc}
\hline Variable & Coefficient & Standard Error & t-Statistic & Probability \\
\hline LG & $0.962^{* * *}$ & 0.498 & 1.929 & 0.081 \\
K & 0.032 & 0.154 & 0.209 & 0.838 \\
ALG & $0.602^{* * *}$ & 0.311 & 1.936 & 0.080 \\
P & $-0.039^{* *}$ & 0.018 & -2.167 & 0.035 \\
TFP & $1.1904^{*}$ & 0.090 & 13.220 & 0.000 \\
RER & 0.247 & 0.163 & 1.512 & 0.159 \\
C & -2.166 & 1.284 & -1.687 & 0.091 \\
& Note: ${ }^{*}, * *$ and & $* *$ denotes significant level at $1 \%, 5 \%$ and $10 \%$ respectively \\
\hline
\end{tabular}

Source, Author computation Using Eviews 9 (2020).

Table 6. The Short-run Estimates.

\begin{tabular}{ccccc}
\hline Variable & Coefficient & Standard Error & t-Statistic & Probability \\
\hline CointEq(e1) & -0.354 & 0.046 & -7.739 & 0.000 \\
D(AG(-1)) & 0.123 & 0.028 & 4.409 & 0.001 \\
D(LG) & 0.474 & 0.161 & 2.944 & 0.013 \\
D(LG(-1)) & 0.120 & 0.125 & 0.961 & 0.357 \\
D(K) & 0.358 & 0.012 & 29.005 & 0.000 \\
D(K(-1)) & 0.210 & 0.038 & 5.499 & 0.000 \\
D(ALG) & -0.277 & 0.101 & -2.743 & 0.019 \\
D(ALG(-1)) & -0.530 & 0.099 & -5.362 & 0.000 \\
D(P) & 0.081 & 0.003 & 26.605 & 0.000 \\
D(P(-1)) & 0.050 & 0.009 & 5.230 & 0.000 \\
D(TFA) & 1.033 & 0.006 & 165.699 & 0.000 \\
D(TFA(-1)) & 0.355 & 0.094 & 3.782 & 0.003 \\
D(RER) & 0.118 & 0.041 & 2.888 & 0.015 \\
D(RER(-1)) & 0.120 & 0.049 & 2.430 & 0.033 \\
\hline
\end{tabular}

Source, Author computation Using Eviews 9 (2020).

As shown in Table 5, except capital (K) and real exchange rate (RER), all the other independent variables are statistically significant. Inflation $(\mathrm{P})$, in the long-run has negative and significant effect on agriculture sector growth of Ethiopia. That means keeping other variables constant, a $1 \%$ increase in the general price level results in a $0.039 \%$ decrease in the growth of agriculture output. This is due to the fact that inflation could have the effect of increasing the cost of inputs (labour, land, capitals, fertilizer, pesticides and herbicides etc.) which in turn creates uncertainty and results slow growth of the agriculture sector. Even though continuing arguments exists about the relationship between agriculture sector growth and inflation, the result found in this study is consistent with the findings of Kaur (2013) who revealed that inflation has negative ef- 
fect on the growth of agriculture sector in India. Moreover, it is in line with the findings of Mkhatshwa et al. (2015) who exhibited that there is a negative relationship between inflation and agriculture sector growth in Swaziland. On the other hand, the finding of this study is in contrast to the finding of Ayyoub (2015) who pointed out that inflation has positive and significant effect on agriculture sector growth of developing economies. The contrasting evidence regarding the effect of inflation on agriculture growth could be due to methodological variation. Overall, the evidence from the ARDL model indicated that in the long-run inflation has negative effect on agriculture sector growth of Ethiopia.

In the long-run, growth of labour force has positive and significant effect on agriculture sector growth of Ethiopia. The result suggests that, everything else equal a $1 \%$ increase in the growth of labour force results in a $0.963 \%$ increase in agriculture sector growth. This result is expected because almost $70 \%$ of labour force in Ethiopia is employed in the agriculture sector and also labour is the main variable input used in agricultural production. The result is consistent with the findings of Khaledi and Shirazi (2013) that exhibited a positive effect of labour force growth on agriculture sector growth of Iran. Arable land as a percentage of total land area has significant and positive long-run relationship with the growth of agriculture sector. Everything else equal, a $1 \%$ increase in the growth of arable land area results in a $0.602 \%$ increase in agriculture sector growth. Previously, it was hypothesized that growth of arable land could play a positive role for the growth of agriculture sector particularly in countries with low technology utilization and extensive agriculture is prevalent.

Total productivity of factors (TPF) has significant and positive effect on agriculture sector growth. The result suggests that other variables constant, a $1 \%$ increase in TPF results in $1.19 \%$ increase in agriculture sector growth. As indicated previously, TPF measure the residual output that is unexplained by labour, capital and land. As a result the sources of this TFP could be fertilizer, credit access, other modern input, and other agriculture productivity enhancing factors. The result in this regard is consistent with the findings of Khaledi and Shirazi (2013) that revealed the positive effect of TFP on agriculture sector growth of Iran. However, capital has insignificant but positive long-run relationship with agriculture sector growth of Ethiopia. The probable explanation is that increasing investment in agriculture sector alone might not increase agriculture sector growth unless complimented with efficient utilization of the investment. Concerning the real exchange rate, it has insignificant long-run relationship with agriculture sector growth of Ethiopia. This could be due to the fact that majority of Ethiopia's export stuffs are agricultural commodities in which its elasticity for exchange rate is low.

ARDL bound cointegration test shown in the previous section indicates the presence of one long-run equilibrium relationship between independent variables and agriculture sector growth. Therefore, ARDL model is estimated to 
evaluate the short run properties of co-integrated series. Harris and Sollis (2003) shown that the VEC model has co-integration relations built into the specification so that it restricts the long run behaviour of endogenous variables to converge into their cointegrating relationships while allowing for short-run adjustment dynamics. This cointegration term is error correction term since the deviation from long-run equilibrium is corrected gradually through a series of partial short-run adjustments. Similarly, ARDL model has short-run dynamics which shows the speed of adjustment towards long-run equilibrium. First, the short run impact of $\mathrm{P}, \mathrm{LG}, \mathrm{ALG}, \mathrm{TFP}, \mathrm{RER}$ and $\mathrm{K}$ on AG is estimated. In estimation of short-run model, optimal lag was determined automatically, and short-run estimates are presented in Table 6 .

The coefficient of the VEC term is significant with magnitude (e1 $=-0.35)$. Also its value is negative and less than one which assurances that agriculture sector growth convergences to its long run equilibrium by $35.4 \%$ each year. However, the speed of adjustment to its own long-run equilibrium is moderately low as it takes nearly 3 years to adjust fully to its long-run equilibrium if shocks are introduced in the model. As presented in Table 6, there is statistically significant and positive short-run relationship between agricultural sector growth and its one-year lagged value. The result suggest that keeping other variables constant, a $1 \%$ increase in the lagged of agriculture sector results a $0.123 \%$ growth of agriculture sector. This indicates that growth in the lag value of agriculture sector increases its current growth which in turn inhibits the structural transformation of the economy. Similarly, agriculture sector growth has significant and positive short-run relationship with labour force growth, capital, inflation, TFP and real exchange rate. Other variables remain constant, a $1 \%$ increase in labour force growth results a $0.474 \%$ increase in agriculture sector growth of Ethiopia in the short-run. Therefore, the dynamics of labour force has positive effect on the growth of agriculture sector growth because in Ethiopia agriculture sector is greatly dominated by labour. Concerning capital, a $1 \%$ increase in gross capital formation as a percentage of GDP and its lag value results a $0.358 \%$ and increase in the growth of agriculture sector, respectively in the short-run. In the short-run, inflation has positive effect on the growth of agriculture sector. The estimated coefficient indicated that other variables kept constant, a $1 \%$ increase in inflation and its first lag results a $0.081 \%$ and $0.050 \%$ increase in agriculture sector growth, respectively. Similar to its long-run effect, in the short-run, TFP has positive effect on agriculture sector growth. That means a $1 \%$ increase in TFP and its lag value results a $1.033 \%$ and $0.355 \%$ increase in agriculture sector growth, respectively. The real exchange rate also positively affects the growth of agriculture in the short-run. The result suggest that a $1 \%$ increase in the real exchange rate and its lag value results a $0.118 \%$ and $0.120 \%$ increase in agriculture sector growth, respectively. On the other hand, in the short-run, arable land growth has significant but negative effect on agriculture sector growth of Ethiopia. The result suggest that $1 \%$ increase arable land as a percentage of total land 
area and its lag value results a $0.277 \%$ and $0.530 \%$ decrease in agriculture sector growth, respectively.

\subsubsection{Diagnostic Tests}

Diagnostic tests are vital to evaluate the validity of long-run and short-run estimates of model, it model stability (Ramsey test), normality, serial autocorrelation, and heteroskedasticity test. The stability of the model is verified by its ability to justify that coefficients of the model are stable over sample interval; otherwise, a shift from one regression scheme to another cannot be located easily. Figure 3 shows the parameter stability test of the model by using CUSUM and CUSUM of squares from recursive estimates. As revealed on figure 4.3 , the CUSUM squares plot bounds within plus and minus 2 standard errors, and the CUSUM plots bounds within the plus and minus 0.4 standard errors. Thus, the two test shows that the parameters are stable over the period under study. The diagnostic test of residuals shows that the model has desirable properties of OLS.

The serial correlation test of the residual series is checked by using the Lagrange Multiplier test developed by Breusch and Godfrey 1978. The null hypothesis ( $\mathrm{H} 0)$ assumes that there is no serial correlation among residual series. If the $\mathrm{P}$-value is greater than $5 \%$ then $\mathrm{H} 0$ is accepted against $\mathrm{H} 1$. As presented in Table 7, the results showed absence of serial correlation.

The heteroskedasticity test of ARDL residuals is checked by Breusch-PaganGodfrey test. Under null hypothesis (Ho), it assumes residuals are homoscedastic against the alternative hypothesis. If $\mathrm{P}$-value is greater than $5 \%$ then $\mathrm{HO}$ is accepted against H1. The test results shown in Table 7 proved residuals series are homoscedastick which allow accepting the null hypothesis. In order to test normality of residual series, Jarque-Bera statistics is used. The null hypothesis of Jarque-Bera ( $\mathrm{H} 0)$ assumes residuals are normally distributed against alternative hypothesis (H1). The decision rule to accept or reject the hypothesis is that if the $\mathrm{P}$-value is greater than $5 \%$, accept $\mathrm{H0}$ and if $\mathrm{P}$-value is less than $5 \%$ then, reject $\mathrm{HO}$ and accept H1. Based on this criteria, as the residual series are satisfied the normality condition.
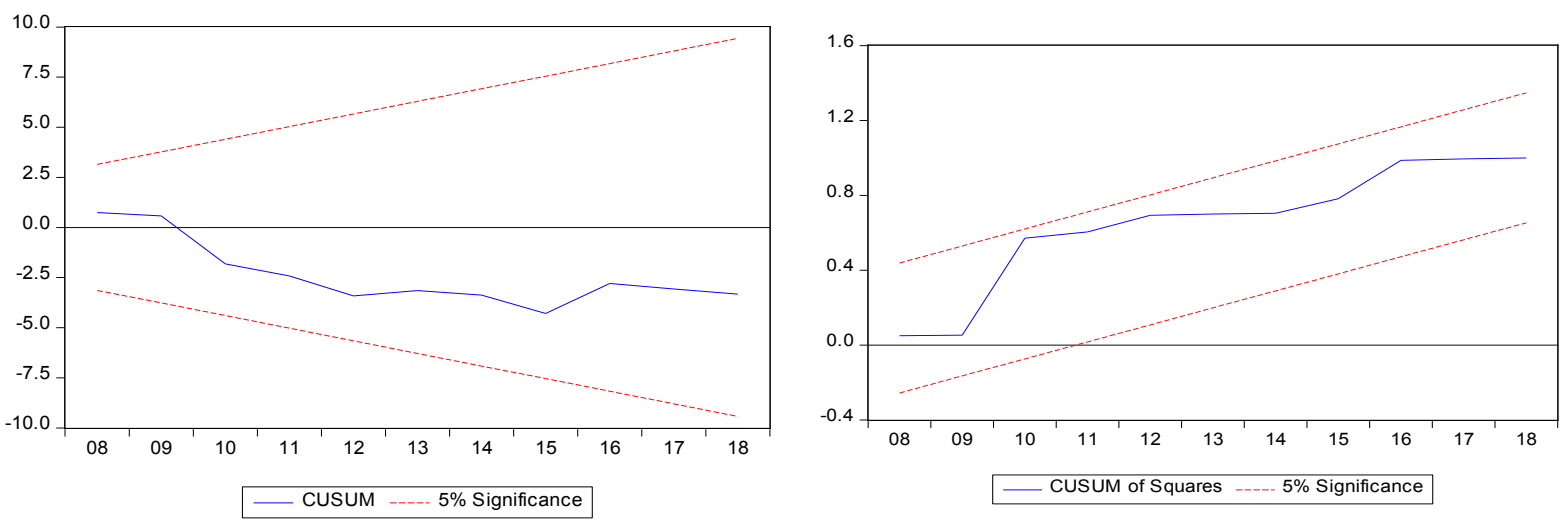

Figure 3. Stability test. Source, Computation Using Eview 9 (2020). 
Table 7. Serial correlation, heteroskedasticity and normality test.

\begin{tabular}{ccc}
\hline Serial Correlation test & F-statistic $=2.88$ & Prob. F $(3,8)=0.13$ \\
& Obs $^{\star}$ R-squared $=8.70$ & Prob. Chi-Square $(3)=0.35$ \\
Heteroskedasticity test & F-statistic $=0.89$ & Prob. F $(24,11)=0.61$ \\
Normality Test & Obs ${ }^{\star}$ R-squared $=23.75$ & Prob. Chi-Square $(24)=0.47$ \\
& Jarque-Bera $=2.95$ & Prob. $=0.23$
\end{tabular}

Source, Author computation Using Eviews 9 (2020).

\section{Conclusion and Recommendation}

This study examined the effects of inflation on agriculture sector growth of Ethiopia from 1980-2018. The empirical base of the study is the neoclassical growth accounting model and estimated by using ARDL model to show the short-run and long-run dynamics of variables. The stationarity test showed the presence of different order of cointegration, $\mathrm{I}(0)$ and $\mathrm{I}(1)$; as a result, the ARDL model is used and the bound test showed the existence of one long-run relationship among variables. The result suggests that agriculture growth has negative and significant long-run relationship with inflation. Therefore, inflation is harmful to the growth of agriculture sector than stimulating it. Total factors productivity, growth of arable land and labour force have positive and significant effect on agriculture sector growth. Concerning the short-run model, there is significant and positive short-run relationship between agricultural growth and its one-year lagged value. Similarly, agriculture growth has significant and positive short-run relationship with labour force growth, capital, inflation, total factors productivity and real exchange rate. But, agriculture growth has significant but, negative short-run relation with that of arable land.

Based on the empirical results of the study, the following policy implications are forwarded. First, government and the monetary authority of Ethiopia should stand to fight inflation. Thus, to raise the growth of agriculture which is vital to lower unemployment and poverty, government should moderate inflation rate using prudent monetary and fiscal policy. Second, government and concerned body should monitor effectiveness and efficiency of agriculture sector investment capacity utilization and their appropriateness should be checked to the context of developing countries. Thirdly, although increasing the size of arable land could increase the growth of agriculture sector, it is not a viable strategy, because land is a fixed input and as the problem is aggravated by the growing population. Thus, intensive agricultural practice along with modern inputs should be encouraged and practiced. As agriculture is labour intensive, increasing the skill and education of labour joining into the agriculture sector will also further increase the growth of agriculture. One way of increasing their skill is through agricultural training and extension service. Finally, total factors productivity is a key for agricultural growth; thus productivity enhancing factors should be applied such as fertilizer, agricultural credit, chemical and etc. 


\section{Conflicts of Interest}

The author declares no conflicts of interest regarding the publication of this paper.

\section{References}

Ahmed, M., Muzib, M., \& Roy, A. (2013). Price-Wage Spiral in Bangladesh: Evidence from ARDL Bound Testing Approach. International Journal of Applied Economics, 10, 77-103.

Ashagrie, D. (2015). Inflation-Growth Nexus in Ethiopia: Evidence from Threshold Auto Regressive Model. JEL Classification, E31, O40.

Ayyoub, M. (2015). Inflation and Sectoral Growth in Developing Economies. PhD Dissertation, Innsbruck: University of Innsbruck.

Bachewe, F. N. (2012). Growth in Total Factor Productivity in the Ethiopian Agriculture Sector: Growth Accounting and Econometric Assessments of Sources of Growth. Development Strategy and Governance Division, International Food Policy Research Institute-Ethiopia Strategy Support Program II, Ethiopia, ESSP II Working Paper 37.

El, M. (2018). Analysis of Factors Affecting the Export Performance in Cambodia: The ARDL Bounds Testing Approach. Journal of Management, Economics, and Industrial Organization, 2, 35-50. https://doi.org/10.31039/jomeino.2018.2.2.3

Fekadu, D. (2012). Relationship between Inflation and Economic Growth in Ethiopia: An Empirical Analysis, 1980-2011. Thesis for the Master of Philosophy in Environmental and Development Economics at University of Oslo.

Getachew, W. (2018). The Relationship between Inflation and Economic Growth in Ethiopia: Budapest International Research and Critics Institute. BIRCI-Journal, 1, 264-271. https://doi.org/10.33258/birci.v1i3.73

Gokal, V., \& Hanif, S. (2004). Relationship between Inflation and Economic Growth. Working Paper No. 2004/04, Suva: Economics Department, Reserve Bank of Fiji.

Harris, R., \& Sollis, R. (2003). Applied Time Series Modelling and Forecasting. Hoboken, NJ: John Wiley and Sons.

Kaur, S. (2013). Inflation Impact on Indian Economy and Agriculture. International Journal of Scientific \& Engineering Research, 4, No. 7.

Khaledi, K., \& Shirazi, A. H. (2013). Estimates of Factors Affecting Economic Growth in the Agricultural Sector in the Fifth Development Plan of Iran (Emphasis on Investment). World Applied Sciences Journal, 22, 1492-1499.

Louhichi, K., Temursho, U., Colen, L., \& Gomez Y Paloma, S. (2019). Upscaling the Productivity Performance of the Agricultural Commercialization Cluster Initiative in Ethiopia. EUR 29950 EN, Luxembourg: Publications Office of the European Union.

Mkhatshwa, Z. S., Tijani, A. A., \& Masuk, M. B. (2015). Analysis of the Relationship between Inflation, Economic Growth and Agricultural Growth in Swaziland from 1980-2013. Journal of Economics and Sustainable Development, 6, 189-204.

National Bank of Ethiopia, NBE. (2015). Annual Report on Ethiopia Economy.

Ndour, C. T. (2017). Effects of Human Capital on Agricultural Productivity in Senegal. World Scientific News, 64, 34-43.

Nkoro, E., \& Uko, A. K. (2016). Autoregressive Distributed Lag (ARDL) Cointegration Technique: Application and Interpretation. Journal of Statistical and Econometric Methods, 5, 63-91. 
NPC National Plan Commission (2016). Growth and Transformation Plan-II of Ethiopia: Volume I Main Text. Addis Ababa.

Oyakhilomen, O., \& Rekwot, Z. G. (2014). The Relationships of Inflationary Trend, Agricultural Productivity and Economic Growth in Nigeria. CBN Journal of Applied Statistics, 5, E31, O11, O47, O55, Q10.

Pesaran, M. H. (1995). Long-Run Structural Modelling. Cambridge: University of Cambridge.

Pesaran, M. H., Shin, Y., \& Smith, R. J. (2001). Bounds Testing Approaches to the Analysis of Level Relationships. Journal of Applied Econometrics, 16, 289-326. https://doi.org/10.1002/jae.616

UNDP (2014). Country Economic Brief of Ethiopia. Analysis Issue No. 1/Feb. 2014.

Verdu, R. G., Cirkel, A. M., Sasahara, A., \& Weisfeld, H. (2019). Importing Inputs for Climate Change Mitigation: The Case of Agricultural Productivity. IMF Working Paper, WP/19/26. https://doi.org/10.5089/9781484393826.001 